\title{
CriptoLab: Um game baseado em Computação Desplugada e Criptografia
}

\author{
Débora Juliane Guerra Marques da Silva ${ }^{1}$, Graziela Ferreira Guarda ${ }^{1}$, Ione \\ Ferrarini Goulart ${ }^{2}$
}

\author{
${ }^{1}$ Departamento de Computação - Universidade Católica de Brasília (UCB) \\ Campus I - QS 07 - Lote 01 - EPCT - Águas Claras - Brasília - DF CEP: 71966-700 \\ ${ }^{2}$ Área de Informação e Comunicação - Instituto Federal de Brasília (IFB) \\ Campus Brasília - SGAN 610 Módulo D, E, F e G - CEP: 70830-450. \\ deborajuliane@gmail.com, grazielafguarda@gmail.com, ionefg@gmail.com
}

\begin{abstract}
The research project called Logicamente was created with the aim of teaching contents of computation focused on the guidelines of computational thinking for children and adolescents of basic education. Among the planned activities, it was idealized the realization of play workshops with the purpose of fixing contents work during the meetings. In this context, came the game CriptoLab that explores encryption in a disrupted computing environment. The present article consists in reporting the experiences about the application of the game in question that has as objective the crossing of a labyrinth whose course will be realized by means of assembly of logical sequences based on the commands of the application of MIT - Scratch.
\end{abstract}

Resumo. O projeto de pesquisa chamado Logicamente foi criado com o objetivo de ensinar conteúdos de computação com enfoque nas diretrizes do pensamento computacional para crianças e adolescentes da educação básica. Dentre as atividades previstas, se idealizou a realização de oficinas lúdicas com o propósito de fixar conteúdos trabalhos durante os encontros. Neste contexto, surgiu o jogo CriptoLab que explora a criptografia em um ambiente de computação desplugada. O presente artigo consiste em relatar as experiências acerca da aplicação do jogo em questão que tem por objetivo a travessia de um labirinto cujo percurso será realizado através de montagem de sequências lógicas baseadas nos comandos do aplicativo do MIT - Scratch.

\section{Introdução}

Os jogos, são uma atividade rica e de grande efeito que respondem às necessidades lúdicas, intelectuais e afetivas. Estimula a vida social e representa, uma importante contribuição na aprendizagem. Através destes, crianças desenvolvem capacidades, conhecimentos, atitudes e habilidades, entre elas, se destacam: o favorecimento da mobilidade, a imaginação, a diversão, a aceitação de regras, o desenvolvimento do raciocínio lógico, entre outros.

Utilizar novos recursos didáticos no contexto educacional é primordial especialmente em um momento em que o uso das tecnologias da informação e conhecimento (TIC's) se faz tão presente no cotidiano desse público infantil (Unesco, 2015). Neste sentido, pode ser destacado o lúdico, como uma maneira de contribuir para 
motivar os estudantes a buscar, pesquisar, gerar novos conhecimentos, trabalhar de forma cooperativa como uma estratégia para manter o educando na escola, não por obrigação, mas por motivação.

Em paralelo, a criptografia pode ser compreendida como um conjunto de métodos e técnicas para cifrar ou codificar informações legíveis por meio de um algoritmo, convertendo um texto original em um texto ilegível, sendo possível mediante o processo inverso a recuperação das informações originais. (Simon, 1999). Incorporar a criptografia aos jogos lúdicos é algo interessante pois irá despertar nos estudantes o interesse por conteúdos de computação que são fundamentais nos dias atuais.

O presente artigo visa contribuir para a construção de um processo de ensinoaprendizagem gamificado, no qual o desenvolvimento do raciocínio lógico e computacional são estimulados através de práticas que abordam a criptografia com uso de sequências lógicas de forma estruturada amparada pela computação desplugada.

O jogo foi uma das atividades realizadas pelo projeto de pesquisa chamado Logicamente que visa contribuir para a construção de um processo de ensinoaprendizagem gamificado, no qual o desenvolvimento do raciocínio lógico e computacional são estimulados com o intuito de contribuir para a melhoria do rendimento escolar dos estudantes no contexto das ciências exatas. As atividades do projeto se baseiam na realização de oficinas em laboratório de informática apoiado pelo uso dos jogos digitais educativos, bem como, por atividades lúdicas - foco do presente trabalho - com o propósito de estimular o desenvolvimento do raciocínio lógico sob a ótica do Pensamento Computacional (PC).

O artigo está dividido da seguinte maneira: a seguir, na Seção 2, é apresentada uma explicação sobre o jogo e a metodologia utilizada, bem como, sua organização estrutural. Os resultados parciais são descritos na Seção 3. Por fim, os objetivos e metas desta experiência serão destacados na Seção 4, de forma a concluir o propósito do jogo diante dos resultados já obtidos, bem como, relatar a perspectiva de resultados futuros e melhorias que poderão ser integradas posteriormente.

\section{Proposta e Metodologia}

A ideia do jogo surgiu oriunda da necessidade de dar continuidade, de maneira prática, a assuntos que foram temas trabalhados pelo projeto Logicamente. Neste aspecto, $\quad \mathrm{o}$ presente jogo tem por objetivo aplicar os conceitos de criptografia e lógica de programação relacionado as habilidades do PC como: Abstração - capacidade de filtrar informações essenciais e descartar as informações desnecessárias em um determinado contexto; Decomposição - dividir um problema grande em partes menores, facilitando sua solução; Coleta de Dados - localizar dados necessários para resolver um problema; e Construção de Algoritmo - sequências de passos ordenados para se atingir um determinado objetivo (Pessoa et al, 2017).

O jogo foi estruturado em cinco partes. As quatro primeiras abrangeram as mesmas orientações: sortear e responder uma questão de raciocínio lógico, decodificar uma mensagem, procurar uma ficha e montar partes de um código fonte - programa desplugado - baseado na linguagem do aplicativo Scratch. Esse processo foi repetido quatro vezes, pois o código foi propositalmente dividido a fim de exercitar mais as capacidades desenvolvidas pelo PC de decomposição. 
Após conclusão dessas quatro primeiras partes, era possível simular a passagem pelo labirinto impresso numa folha de papel A4, que se refere a quinta parte do jogo conforme demonstrado na Tabela 1 a seguir.

Tabela 1. Esquema das Fases do Jogo.

\begin{tabular}{|c|c|c|c|c|c|}
\hline Ptapa 1 & Parte 1: & Parte 2: & Parte 3: & Parte 4: & Parte 5: \\
\hline questão & $\begin{array}{c}\text { Responder } \\
\text { questão }\end{array}$ & $\begin{array}{c}\text { Responder } \\
\text { questão }\end{array}$ & $\begin{array}{c}\text { Responder } \\
\text { questão }\end{array}$ & $\begin{array}{c}\text { Atravessar } \\
\text { o labirinto }\end{array}$ \\
\hline Etapa 2 & $\begin{array}{c}\text { Decodificar } \\
\text { mensagem }\end{array}$ & $\begin{array}{c}\text { Decodificar } \\
\text { mensagem }\end{array}$ & $\begin{array}{c}\text { Decodificar } \\
\text { mensagem }\end{array}$ & $\begin{array}{c}\text { Decodificar } \\
\text { mensagem }\end{array}$ & - \\
\hline Etapa 3 & $\begin{array}{c}\text { Buscar a ficha } \\
\text { e trocar pelo } \\
\text { envelope }\end{array}$ & $\begin{array}{c}\text { Buscar a ficha } \\
\text { e trocar pelo } \\
\text { envelope }\end{array}$ & $\begin{array}{c}\text { Buscar a ficha } \\
\text { e trocar pelo } \\
\text { envelope }\end{array}$ & $\begin{array}{c}\text { Buscar a ficha } \\
\text { e trocar pelo } \\
\text { envelope }\end{array}$ & - \\
\hline Etapa 4 & $\begin{array}{c}\text { Montar trecho } \\
\text { do código }\end{array}$ & $\begin{array}{c}\text { Montar trecho } \\
\text { do código }\end{array}$ & $\begin{array}{c}\text { Montar trecho } \\
\text { do código }\end{array}$ & $\begin{array}{c}\text { Montar trecho } \\
\text { do código }\end{array}$ & - \\
\hline
\end{tabular}

O lúdico foi realizado em uma sala de aula - Figura 1. O público-alvo foram estudantes dos $5^{\circ}$ e $6^{\circ}$ ano do ensino fundamental de uma escola particular do Distrito Federal (DF). Preliminarmente, dezesseis fichas foram entregues para quatro funcionários da escola que se encontravam em localizações bem conhecidas pelos estudantes, sendo 4 fichas para cada funcionário referente a cada uma das 4 etapas (Tabela 1).

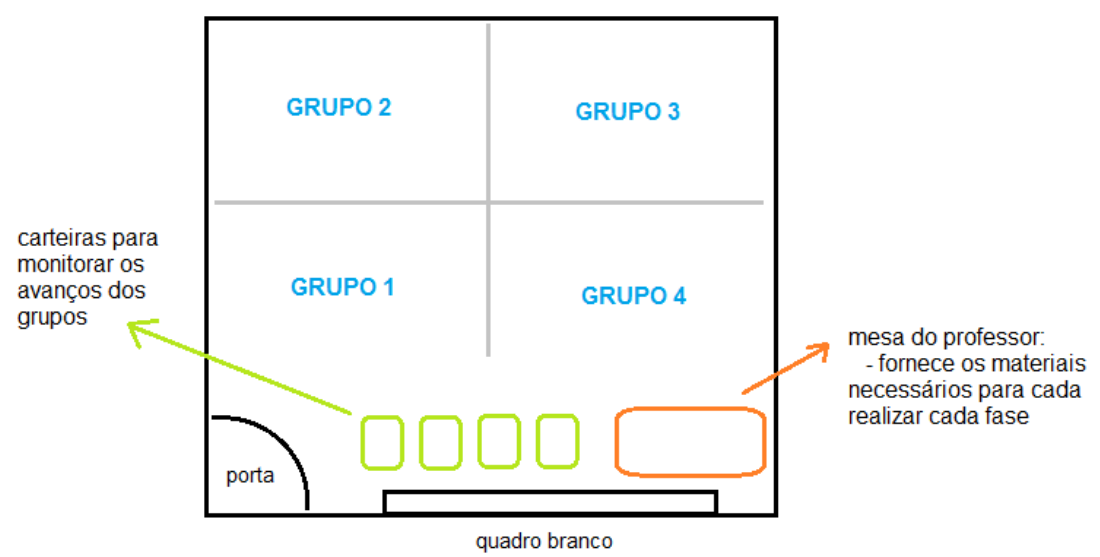

Figura 1. Organização do Ambiente Utilizado.

A turma foi dividida em quatro grupos compostos por quatro a cinco estudantes cada. Cada grupo se reuniu em um canto da sala conforme o exposto na Figura 1 e, antes do jogo começar, cada um deles escolheu um representante para sortear as questões e outro para exercer a função de "corredor" - o corredor tinha a responsabilidade de correr atrás dos funcionários da escola que estavam com as fichas para recolhê-las.

Posteriormente, as fichas seriam trocadas pelos envelopes que continha trechos de código baseado no aplicativo Scratch, que seriam utilizadas na etapa seguinte conforme demonstrado na Figura 2 - a esquerda acima os envelopes, a esquerda abaixo parte de trechos de código e a direita, o um exemplo de esquema lógico montado por uma das equipes. 


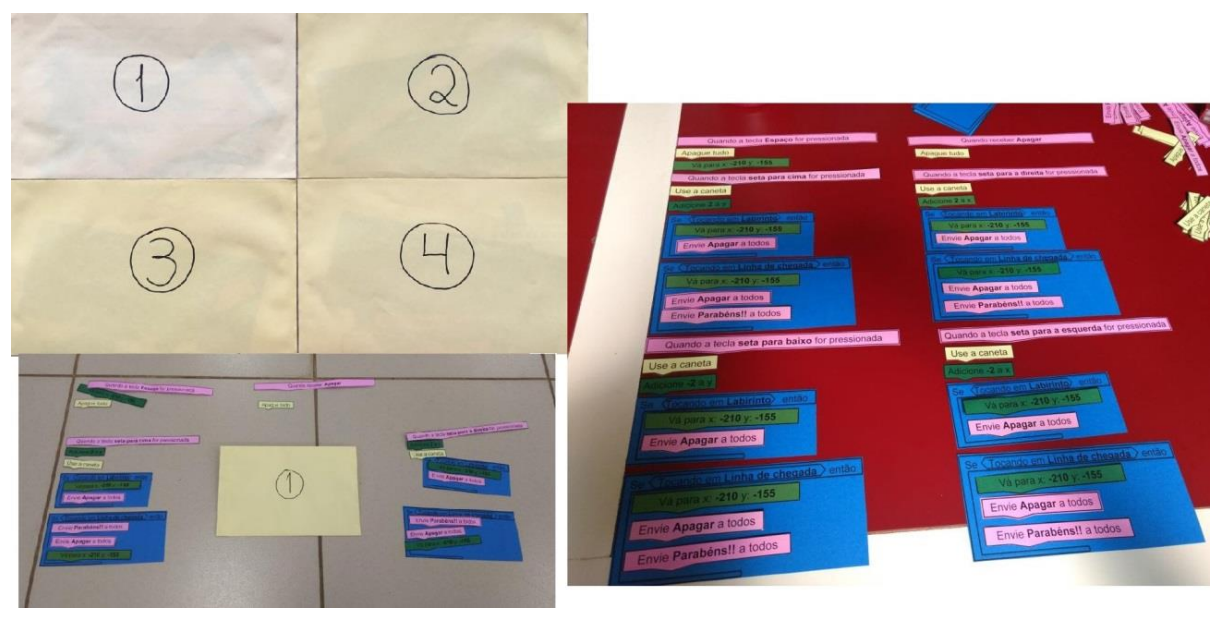

Figura 2. Etapas do Jogo.

Os responsáveis pela aplicação e monitoramento do jogo ficaram reunidos na mesa do professor (Figura 1), onde ocorreram os sorteios das questões, as correções das mesmas e as decodificações das mensagens, assim como, ficaram responsáveis pelo recebimento das fichas que dava acesso os envelopes com os trechos de código necessários para que a travessia pelo labirinto fosse possível. No total, foi necessário que cada grupo recolhesse quatro envelopes. Em paralelo, para monitorar o avanço de cada equipe, foi disponibilizada uma carteira para cada grupo, onde as atividades concluídas foram depositadas.

A primeira etapa da primeira parte do jogo se referiu ao sorteio de uma questão que deveria ser respondida pelas equipes. As perguntas foram de múltipla escolha e tinham como assuntos o raciocínio lógico e matemático alinhado com os conhecimentos acadêmicos dos estudantes de $5^{\circ}$ e $6^{\circ}$ anos do ensino fundamental e demais temas trabalhados pelo projeto Logicamente. As questões foram retiradas e adaptadas de sítios de concursos públicos e desafios. Assim que finalizada as respostas, as mesmas eram corrigidas e, estando corretas, a próxima fase era desbloqueada. A tabela 2 mostra o conjunto de questões que foram respondidas pelos estudantes na fase 1 .

Tabela 2. Questões Fase 1.

\begin{tabular}{|c|c|c|c|}
\hline $\mathbf{N}^{\circ}:$ & Enunciado: & Alternativas: & Gabarito: \\
\hline 1 & $\begin{array}{l}\text { Considere a tabela de preços, por quilo, do empório do Seu } \\
\text { Joaquim, para resolver a questão: } \\
\begin{array}{l}\text { ARROZ } \\
\text { FUBÁ }\end{array} \quad \mathrm{R} \$ 1,90 \\
\text { FEIJÃO } \quad \mathrm{R} \$ 3,40 \\
\text { FARINHA } \quad \mathrm{R} \$ 2,10 \\
\text { Um freguês comprou } 5 \mathrm{Kg} \text { de farinha, } 3 \mathrm{Kg} \text { de fubá e } 1 \mathrm{Kg} \text { de feijão } \\
\text { e ainda sobrou dinheiro para comprar } 10 \mathrm{Kg} \text { de arroz. O total de } \\
\text { dinheiro desse freguês é: }\end{array}$ & $\begin{array}{l}\text { a) } R \$ 17,50 \\
\text { b) } R \$ 29,50 \\
\text { c) } R \$ 36,50 \\
\text { d) } R \$ 35,50\end{array}$ & Letra C \\
\hline 2 & $\begin{array}{l}\text { Em um jogo de futebol, o } 1^{\circ} \text { gol da partida foi marcado aos } 5 \\
\text { minutos do } 1^{\circ} \text { tempo e o } 2^{\circ} \text { gol foi marcado faltando exatamente } 7 \\
\text { minutos para o término do } 2^{\circ} \text { tempo. Sabendo que cada tempo } \\
\text { durou exatamente } 45 \text { minutos e que o intervalo durou exatamente } \\
15 \text { minutos, então, entre o } 1^{\circ} \text { e o } 2^{\circ} \text { gol, passou-se um tempo total } \\
\text { de: }\end{array}$ & $\begin{array}{l}\text { a) } 1 \mathrm{~h} \text { e } 25 \mathrm{~m} \\
\text { b) } 1 \mathrm{~h} \text { e } 30 \mathrm{~m} \\
\text { c) } 1 \mathrm{~h} \text { e } 33 \mathrm{~m} \\
\text { d) } 1 \mathrm{~h} \text { e } 35 \mathrm{~m} \\
\text { e) } 1 \mathrm{~h} \text { e } 38 \mathrm{~m}\end{array}$ & Letra C \\
\hline
\end{tabular}




\begin{tabular}{|c|c|c|c|}
\hline 3 & $\begin{array}{l}\text { Sabe-se que Ana é a irmã mais nova e que possui mais seis irmãos. } \\
\text { Considere que todos nasceram em anos pares e com uma diferença } \\
\text { de dois anos entre cada um deles. Se Ana nasceu em 2002, quantos } \\
\text { anos o seu irmão mais velho completará em 2015? }\end{array}$ & $\begin{array}{l}\text { a) } 22 \text { anos } \\
\text { b) } 25 \text { anos } \\
\text { c) } 24 \text { anos } \\
\text { d) } 23 \text { anos }\end{array}$ & Letra B \\
\hline 4 & $\begin{array}{l}\text { Alice nasceu no dia } 1^{\circ} \text { de março de } 1980 . \text { Em que ano ela } \\
\text { completará } 67 \text { anos? }\end{array}$ & $\begin{array}{l}\text { a) } 1997 \\
\text { b) } 2007 \\
\text { c) } 2017 \\
\text { d) } 2047\end{array}$ & Letra D \\
\hline 5 & $\begin{array}{l}\text { Dirigindo ao caixa de uma papelaria, o comprador disse: } \\
\text { "Gostaria de comprar } 2 \text { pastas com elástico a } R \$ 1,00 \text { cada, } 3 \\
\text { canetas coloridas a } R \$ 3,00 \text { cada e } 4 \text { borrachas, mas o preço das } \\
\text { borrachas eu não sei". } \\
\text { O caixa entregou uma conta ao comprador de } \mathrm{R} \$ 19,00 \text {. De acordo } \\
\text { com texto, o valor de cada borracha, em reais, é: }\end{array}$ & $\begin{array}{l}\text { a) } 2,20 \\
\text { b) } 1,50 \\
\text { c) } 1,70 \\
\text { d) } 3,00 \\
\text { e) } 2,00\end{array}$ & Letra $\mathrm{E}$ \\
\hline 6 & $\begin{array}{l}\text { Em um determinado país, as temperaturas registradas em graus } \\
\text { Celsius, em certo período do dia, foram as seguintes: }-4^{\circ},-1^{\circ}, 0^{\circ},- \\
2^{\circ},-3^{\circ} \text { e }-5^{\circ} \text {. A temperatura, em graus Celsius, mais alta registrada } \\
\text { nesse país foi de: }\end{array}$ & $\begin{array}{l}\text { a) } 0^{\circ} \\
\text { b) }-5^{\circ} \\
\text { c) }-1^{\circ} \\
\text { d) }-4^{\circ} \\
\text { e) }-3^{\circ}\end{array}$ & Letra A \\
\hline 7 & $\begin{array}{l}\text { Joãozinho decidiu fazer uma viagem para poder pescar no rio } \\
\text { durante cinco dias. } \\
\text { No primeiro dia, ele pescou } 20 \text {. Já no segundo, pescou } 48 \text { peixes. } \\
\text { No terceiro, conseguiu } 65 \text {. No quarto dia, foram } 54 \text {. Finalmente, no } \\
\text { quinto dia ele conseguiu pescar } 38 \text { peixes. } \\
\text { Foram pescadas quantidades que representam números divisíveis } \\
\text { por } 3 \text { nos dias: } \\
\text { Obs.: números divisíveis por } 3 \text { são aqueles que, ao serem divididos } \\
\text { por } 3 \text {, o resto da divisão é } 0 \text {. }\end{array}$ & $\begin{array}{l}\text { a) } 1 \text { e } 2 \\
\text { b) } 2 \text { e } 4 \\
\text { c) } 3 \text { e } 5 \\
\text { d) } 4 \text { e } 5 \\
\text { e) } 1 \text { e } 3\end{array}$ & Letra B \\
\hline 8 & $\begin{array}{l}\text { Rafael e Orlando combinaram de jogar sinuca valendo } \mathrm{R} \$ 2,00 \text { ao } \\
\text { vencedor de cada partida. Rafael chegou para o jogo com } \mathrm{R} \$ 60,00 \\
\text { e Orlando, com } \mathrm{R} \$ 28,00 \text {. Ao final do jogo, ambos ficaram com } \\
\text { quantias iguais. } \\
\text { Nesse caso hipotético, é correto afirmar que a quantidade de } \\
\text { partidas que Orlando ganhou a mais que Rafael foi igual a: }\end{array}$ & $\begin{array}{l}\text { a) } 4 \\
\text { b) } 5 \\
\text { c) } 6 \\
\text { d) } 7 \\
\text { e) } 8\end{array}$ & Letra $\mathrm{E}$ \\
\hline 9 & $\begin{array}{l}\text { Gilberto precisa embalar seis dezenas de ovos em caixas com } \\
\text { capacidade para uma dúzia ovos cada. A quantidade de caixas } \\
\text { necessárias para que Gilberto realize essa tarefa é igual a: }\end{array}$ & $\begin{array}{l}\text { a) } 3 \\
\text { b) } 5 \\
\text { c) } 4 \\
\text { d) } 6\end{array}$ & Letra B \\
\hline 10 & O dobro do triplo da metade de 10 é: & $\begin{array}{l}\text { a) } 2,5 \\
\text { b) } 120 \\
\text { c) } 90 \\
\text { d) } 100 \\
\text { e) } 30\end{array}$ & Letra $\mathrm{E}$ \\
\hline 11 & $\begin{array}{l}\text { Assinale a alternativa em que os números estão dispostos do menor } \\
\text { para o maior. }\end{array}$ & $\begin{array}{l}\text { a) } \frac{1}{4}: \frac{3}{10}: \frac{13}{10} \\
\text { b) } \frac{1}{10}: \frac{1}{4} ; \frac{13}{10} \\
\text { c) } \frac{13}{10}: \frac{1}{4}: \frac{3}{10} \\
\text { d) } \frac{13}{10} ; \frac{a}{10}: \frac{1}{4} \\
\text { e) } \frac{a}{10}: \frac{13}{10}: \frac{1}{4}\end{array}$ & Letra A \\
\hline 12 & $\begin{array}{l}\text { Abel tem } 1,80 \text { metros de altura, Bia tem } 1,58 \text { metros, Carlos tem } \\
1,75 \text { metros, Duda tem } 1,65 \text { metros e Edu tem } 1,98 \text { metros. O mais }\end{array}$ & $\begin{array}{l}\text { a) Abel } \\
\text { b) Duda }\end{array}$ & Letra $\mathrm{C}$ \\
\hline
\end{tabular}




\begin{tabular}{|c|c|c|c|}
\hline & baixo entre eles é: & $\begin{array}{l}\text { c) Bia } \\
\text { d) Edu } \\
\text { e) Carlos }\end{array}$ & \\
\hline 13 & $\begin{array}{l}\text { Cada um dos tempos de um jogo de futebol tem } 45 \text { minutos. Se a } \\
\text { partida começou às } 15 \text { horas e } 25 \text { minutos, o primeiro tempo } \\
\text { terminará às: }\end{array}$ & $\begin{array}{l}\text { a) } 16 \mathrm{~h} 10 \mathrm{~m} \\
\text { b) } 16 \mathrm{~h} \\
\text { c) } 16 \mathrm{~h} 25 \mathrm{~m} \\
\text { d) } 16 \mathrm{~h} 45 \mathrm{~m} \\
\text { e) } 16 \mathrm{~h} 15 \mathrm{~m}\end{array}$ & Letra A \\
\hline 14 & $\begin{array}{l}\text { Um escritório de contabilidade imprime cerca de } 15 \text { páginas por dia } \\
\text { útil. Considerando que o ano possui } 250 \text { dias úteis, pode-se afirmar } \\
\text { que o total de páginas impressas será: }\end{array}$ & $\begin{array}{l}\text { a) } 2.000 \\
\text { b) } 2.500 \\
\text { c) } 2.750 \\
\text { d) } 3.500 \\
\text { e) } 3.750\end{array}$ & Letra $\mathrm{E}$ \\
\hline 15 & $\begin{array}{l}\text { Ana pretende viajar nas férias para São Paulo. Para conseguir } \\
\text { viajar, ela precisa juntar } \mathrm{R} \$ 1.200,00 \text {. O salário de Ana é R\$ } \\
1.000,00 \text { e ela só pode reservar mensalmente para a viagem a quinta } \\
\text { parte do seu salário. Em quantos meses Ana conseguirá realizar sua } \\
\text { viagem? }\end{array}$ & $\begin{array}{l}\text { a) } 3 \text { meses } \\
\text { b) } 4 \text { meses } \\
\text { c) } 5 \text { meses } \\
\text { d) } 6 \text { meses } \\
\text { e) } 7 \text { meses }\end{array}$ & Letra D \\
\hline 16 & $\begin{array}{l}\text { Um supermercado está realizando uma promoção para os } \\
\text { consumidores. A cada R\$ 100,00 em compras, o cliente ganha um } \\
\text { desconto de } \mathrm{R} \$ 5,00 \text {. Se um cliente fizer uma compra de } \mathrm{R} \$ 800,00 \\
\text { o desconto total será: }\end{array}$ & $\begin{array}{l}\text { a) } R \$ 60,00 \\
\text { b) } R \$ 50,00 \\
\text { c) } R \$ 40,00 \\
\text { d) } R \$ 80,00 \\
\text { e) } R \$ 70,00\end{array}$ & Letra $\mathrm{C}$ \\
\hline
\end{tabular}

A segunda etapa do jogo, consiste em decodificar uma mensagem, cujo conteúdo revelava qual funcionário da escola estaria com a ficha responsável por liberar a etapa seguinte conforme demonstrado na Figura 3 - exemplo de mensagem criptografada de uma das equipes:

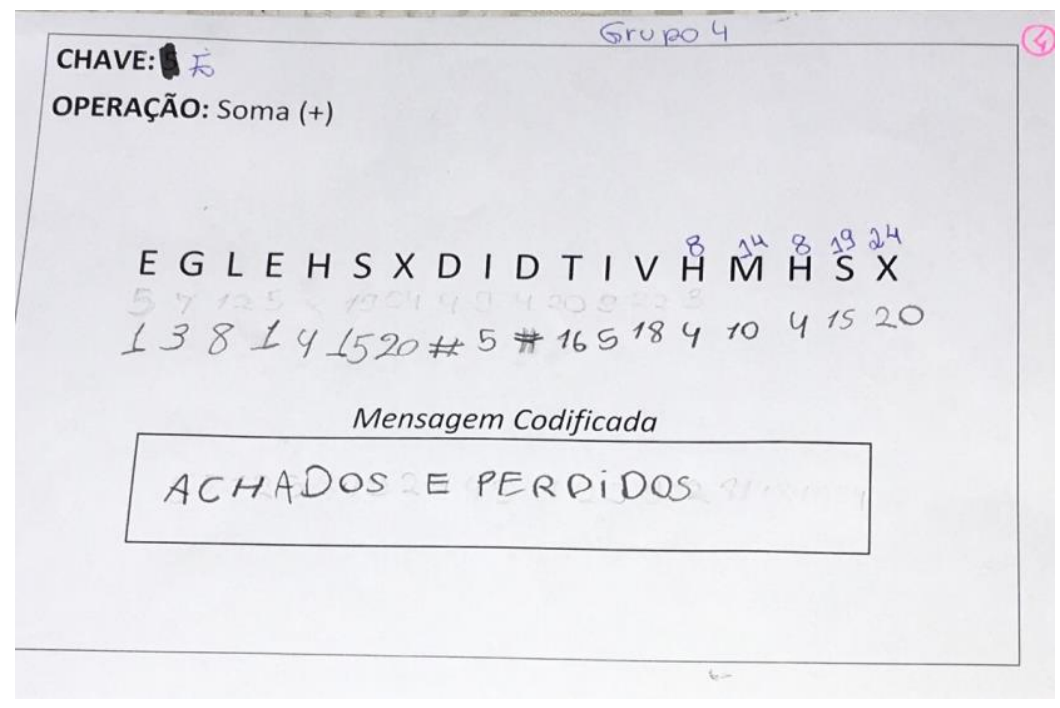

Figura 3. Mensagem Codificada.

Já na terceira etapa, o estudante "corredor" troca a ficha pelo envelope com os trechos de código que tornam possível a passagem pelo labirinto. Posteriormente, a quarta etapa se refere à montagem do código de modo que, o acesso à próxima parte do jogo só será permitido se a construção do mesmo estiver correta. Esse conjunto de etapas se repete quatro vezes, mudando apenas o conteúdo. 
Depois que as quatro primeiras etapas foram concluídas, os grupos receberam uma folha com o labirinto e com a tabela que deveria ser escrita a solução do problema - Figura 4, que consistiu em expor quantas vezes e quais seriam as teclas que devem ser acionadas, simulando como se a atividade fosse no computador (cima, baixo, esquerda e direita). Essas instruções foram trabalhadas na aula anterior ao lúdico e reforçadas no dia da aplicação dinâmica, um aspecto a ser destacado é que todos os conteúdos abordados no jogo foram previamente trabalhados em sala, durante as atividades do projeto Logicamente.

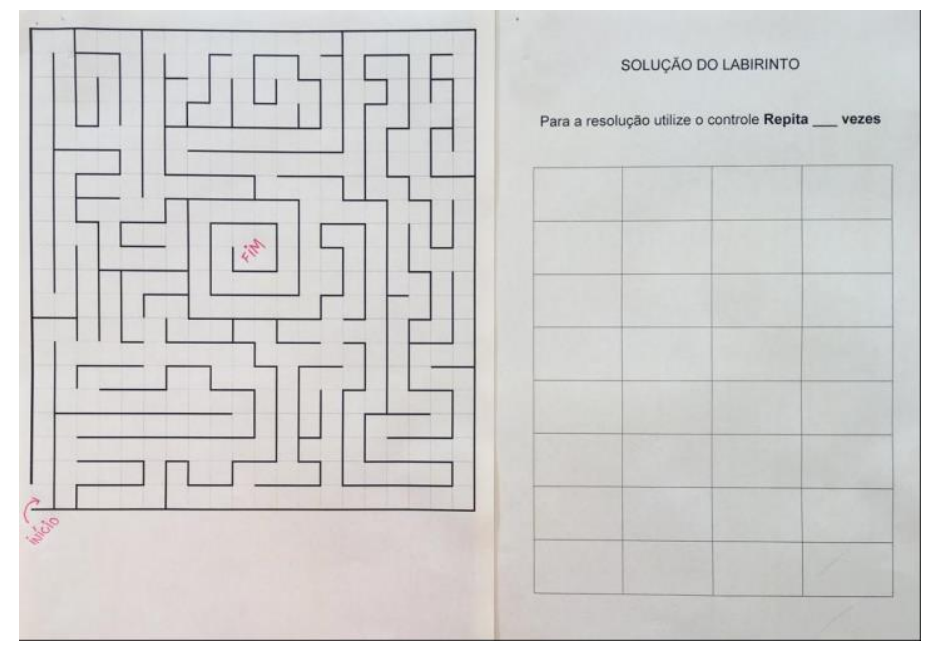

Figura 4. Labirinto e Tabela de Solução.

\section{Resultados e Discussões}

O CriptoLab foi jogado por um total de quarto equipes, cada equipe continha entre 4 e 5 integrantes. Foi estabelecido como regra geral que cada fase não poderia ultrapassar 20 minutos e esse tempo foi cronometrado por equipe. Todas as equipes conseguiram concluir as 5 fases do jogo. A Tabela 3 abaixo mostra o tempo que cada equipe gastou na finalização de cada fase:

Tabela 3. Tempo Gasto por Equipe.

\begin{tabular}{|l|l|l|l|l|}
\hline Fase / Grupo: & $\mathbf{1}$ & $\mathbf{2}$ & $\mathbf{3}$ & $\mathbf{4}$ \\
\hline $\mathbf{1}$ & $19 \mathrm{~min}$ & $20 \mathrm{~min}$ & $20 \mathrm{~min}$ & $18 \mathrm{~min}$ \\
\hline $\mathbf{2}$ & $18 \mathrm{~min}$ & $17 \mathrm{~min}$ & $18 \mathrm{~min}$ & $17 \mathrm{~min}$ \\
\hline $\mathbf{3}$ & $15 \mathrm{~min}$ & $18 \mathrm{~min}$ & $18 \mathrm{~min}$ & $13 \mathrm{~min}$ \\
\hline $\mathbf{4}$ & $17 \mathrm{~min}$ & $18 \mathrm{~min}$ & $19 \mathrm{~min}$ & $13 \mathrm{~min}$ \\
\hline $\mathbf{5}$ & $6 \mathrm{~min}$ & $6 \mathrm{~min}$ & $7 \mathrm{~min}$ & $5 \mathrm{~min}$ \\
\hline $\mathbf{\Sigma}$ tempo & $75 \mathrm{~min}$ & $79 \mathrm{~min}$ & $82 \mathrm{~min}$ & $66 \mathrm{~min}$ \\
\hline
\end{tabular}

De acordo com o exposto na Tabela 3, a equipe vencedora foi a equipe 4, que finalizou todas as etapas do jogo em um total de 66 minutos e a equipe que concluiu por último demorou 82 minutos. Em complemento, a Tabela 4 demonstra o conjunto de características de cada equipe formada.

Tabela 4. Características das Equipes.

\begin{tabular}{|l|l|l|l|l|}
\hline $\begin{array}{l}\text { Características } \\
\text { / Grupo: }\end{array}$ & Sexo: & Deveres de casa: & Concentração: & $\begin{array}{l}\text { Organização / Divisão } \\
\text { das Tarefas: }\end{array}$ \\
\hline 1 & Masculino & Entregavam parcialmente & Alta & Boa \\
\hline
\end{tabular}




\begin{tabular}{|l|l|l|l|l|}
\hline 2 & Misto & $\begin{array}{l}\text { Não entregavam as } \\
\text { atividades }\end{array}$ & Alta & Ótima \\
\hline 3 & Masculino & $\begin{array}{l}\text { Não entregavam as } \\
\text { atividades }\end{array}$ & Média & Ótima \\
\hline 4 & Feminino & $\begin{array}{l}\text { Entregavam com } \\
\text { frequência as atividades } \\
\text { propostas }\end{array}$ & Alta \\
\hline
\end{tabular}

Considerando os dados da Tabela 4, observa-se que a equipe campeã foi composta exclusivamente por estudantes do sexo feminino, cuja entregas dos deveres de casa em relação as atividades como um todo do projeto Logicamente eram frequentes - o que justifica uma concentração mais alta por parte desta equipe, uma vez que, os conhecimentos prévios já estavam mais evoluídos. Consequentemente, se observou uma melhor organização e divisão das tarefas durante a execução do jogo.

Durante a execução do jogo, foi possível perceber que os estudantes apresentaram diferentes tipos de dificuldade, algumas em relação ao raciocínio lógico matemático, outros em relação a montagem das sequências do código fonte, e também, em relação a divisão das tarefas.

Aqueles que tiveram dificuldade com a parte matemática do jogo foram aqueles estudantes com perfil mais dispersos em sala de aula e os que faltaram à aula de criptografia. Os estudantes que tiveram mais dificuldade com a montagem do código fonte foram aqueles que não costumavam entregar os deveres de casa, os deveres neste caso, se referiram as atividades usando o aplicativo Scratch.

Ainda em relação às dificuldades observadas, destacam-se: dispersão, dificuldade de compreensão dos comandos do Scratch - essa dificuldade é devida a falta de prática de exercícios na ferramenta, que se configura em dificuldades conceituais dos conteúdos ministrados. Nos casos em que a mensagem criptografada ultrapassava dez caracteres, se percebeu ansiedade na solução e alguns grupos tentaram burlar os cálculos usando adivinhação de padrões.

Dentre os aspectos positivos, se pode destacar que todas as equipes conseguiram concluir as 5 fases do jogo com sucesso dentro do tempo estabelecido. A divisão do problema em partes menores facilitou o trabalho das equipes. Em relação ao aprendizado dos conteúdos necessários, se observou que os estudantes que se dedicaram a aprender sobre o tema anteriormente a dinâmica, passaram pelas fases com relativa facilidade.

A inclusão da criptografia como parte das atividades foi outro aspecto muito positivo, pois instigou a curiosidade dos estudantes e o despertar para estudos acerca do tema. Além disso, foi observado que, a divisão de um grande problema em partes menores, colaborou positivamente para que todas as equipes concluíssem o jogo. Essa condição de dividir um problema em partes menores vai em consonância com o documento - Referenciais de formação em computação: Educação Básica (SBC, 2017).

Por fim, foi aplicado um instrumento de avaliação, cujo objetivo foi mapear as opiniões dos estudantes que participaram da atividade para fins de ajustes e correções futuras tanto do jogo quanto em relação as atividades do projeto como um todo conforme o exposto na Tabela 5. 
Tabela 5. Avaliação do CriptoLab e Atividades do Projeto.

\begin{tabular}{|c|c|c|c|c|}
\hline Q: & Enunciado: & Resposta 1: & Resposta 2: & Resposta 3: \\
\hline 1 & $\begin{array}{l}\text { Como foi trabalhar em } \\
\text { equipe no lúdico? }\end{array}$ & Difícil (3) & Fácil (17) & Indiferente $(0)$ \\
\hline 2 & $\begin{array}{l}\text { As aulas do projeto } \\
\text { ajudaram no lúdico? }\end{array}$ & $\begin{array}{l}\text { Sim, bastante } \\
(20)\end{array}$ & Não (0) & $\begin{array}{l}\text { Não, o assunto dado em } \\
\text { sala não foi o suficiente } \\
\text { para ajudar no lúdico }(0)\end{array}$ \\
\hline 3 & $\begin{array}{l}\text { Em que você teve mais } \\
\text { dificuldade? }\end{array}$ & Matemática (10) & \begin{tabular}{lr}
\multicolumn{2}{l}{ Na utilização da } \\
lógica & para \\
resolver & os \\
desafios (8) & \\
\end{tabular} & Matemática e lógica (2) \\
\hline 4 & $\begin{array}{l}\text { Qual foi a sua maior } \\
\text { dificuldade para montar o } \\
\text { labirinto? }\end{array}$ & $\begin{array}{l}\text { Achar } \quad \text { a } \\
\text { sequência certa } \\
\text { para montar o } \\
\text { algoritmo (10) }\end{array}$ & $\begin{array}{ll}\text { Identificar } & \text { os } \\
\text { tipos } & \text { de } \\
\text { comando (8) } & \end{array}$ & Tempo insuficiente (2) \\
\hline 5 & $\begin{array}{l}\text { Ao participar do projeto o } \\
\text { seu rendimento escolar } \\
\text { aumentou? }\end{array}$ & $\begin{array}{l}\text { Sim, consigo } \\
\text { resolver } \\
\text { problemas com } \\
\text { mais rapidez } \\
(16)\end{array}$ & $\begin{array}{ll}\text { Não, } & \text { o } \\
\text { rendimento } & \\
\text { continua } & \text { o } \\
\text { mesmo (4) } & \end{array}$ & $\begin{array}{l}\text { Não, o rendimento caiu } \\
(0)\end{array}$ \\
\hline 6 & 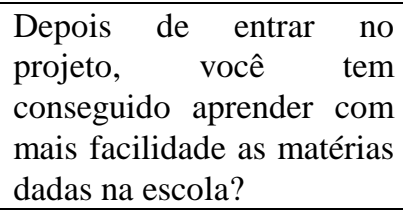 & $\operatorname{Sim}(18)$ & Não (1) & $\begin{array}{l}\text { Não, continuo do mesmo } \\
\text { jeito em que entrei no } \\
\text { projeto (1) }\end{array}$ \\
\hline 7 & $\begin{array}{l}\text { Você consegue aplicar o } \\
\text { conteúdo dado no projeto } \\
\text { em seu dia a dia? }\end{array}$ & $\operatorname{Sim}(15)$ & Não (4) & $\begin{array}{l}\text { Tenho dificuldades para } \\
\text { aplicar o conteúdo no dia } \\
\text { a dia (1) }\end{array}$ \\
\hline
\end{tabular}

Os números entre parênteses nas colunas de respostas representam as quantidades de votos que cada alternativa recebeu. De acordo com os dados da Tabela 5, os estudantes não apresentaram dificuldades para trabalhar em equipe, as aulas e conteúdos estudados preliminarmente contribuíram de forma efetiva para o bom andamento da atividade proposta, foi identificado que existem dificuldades tanto da matemática quanto da lógica na mesma proporção, do mesmo modo, que houve um equilíbrio entre a dificuldade da organização das sequências lógicas e em relação ao uso dos comandos do Scratch.

Em relação as impressões do impacto das atividades do projeto, se percebe, de acordo com a visão dos estudantes, que o rendimento escolar aumentou, que a facilidade de compreensão de conteúdos escolares também foi aumentada e que eles conseguem fazer a relação dos conteúdos aprendidos com a vida real.

\section{Conclusões}

O projeto Logicamente tem como finalidade motivar crianças e adolescentes a aprender programação, lógica e assuntos relacionados ao pensamento computacional de maneira criativa, que são habilidades essenciais para a vida de qualquer indivíduo. Se estima com a inserção o PC no âmbito da educação básica, oportunizar a formação de habilidades e competências computacionais, apoiando a ciência e suas áreas de conhecimento. Essas habilidades e competências potencializam a capacidade de resolver problemas. 
Ações nesse sentido vão em consonância com o que já vem sendo praticado em diversos países, como por Alemanha, Argentina, Austrália, Coreia do Sul, Escócia, França, Inglaterra, Estados Unidos da América, Finlândia, Grécia, Índia, Israel, Japão, e Nova Zelândia, entre outros, que adotaram o ensino de computação nas escolas para desenvolver habilidades relacionadas à resolução de problemas complexos. (SBC, 2017).

O jogo teve por objetivo aplicar os conceitos de criptografia relacionado as habilidades do PC. As crianças, hoje, já nascem imersas em um mundo digital, mas, ao contrário do que se possa imaginar, elas não conhecem o funcionamento desse mundo, apenas utilizam suas ferramentas passivamente. A opção pela inclusão do tema criptografia foi de grande valia para que pudesse ser abordado com o público-alvo posteriormente, assuntos como a segurança eletrônica, que envolve questões importantes sobre os riscos que somos expostos ao utilizar as tecnologias, os quais se pode destacar: casos de violação de contas bancárias, acesso a informações sigilosas, invasão e destruição de sistemas, entre outros.

De acordo com os resultados expostos no capítulo 3 do presente artigo, o jogo foi considerado uma iniciativa interessante, que despertou curiosidade pelos temas abordados, interesse em pesquisas sobre o tema e favoreceu a compreensão dos assuntos relacionados reforçando os conteúdos trabalhados pelo projeto Logicamente.

\section{Referências Bibliográficas}

UNESCO "TIC na educação do Brasil", http://www.unesco.org/new/pt/brasilia/communication-and-information/access-toknowledge/ict-in-education/, Novembro.

Pessoa, F. I. R; Araújo, A. S. O.; Andrade W. L.; Guerrero, D. D. S (2017) "T-mind: um Aplicativo Gamificado para Estímulo ao Desenvolvimento de Habilidades do Pensamento Computacional". In Anais do SBIE. DOI: 10.5753/cbie.sbie.2017.645.

Sociedade Brasileira de Computação (2017) Referenciais de Formação em Computação: Educação Básica. http://www.sbc.org.br/noticias/10-slideshow-noticias/1996referenciais-de-formacao-em-computacao-educacao-basica/, Julho.

Simon S. (1999). The Code Book. Fourth Estate, 1st edition. 